\title{
FAKTOR PENUNJANG DAN PENGHAMBAT USAHATANI STROBERI DI KELURAHAN RURUKAN DAN RURUKAN SATU, KECAMATAN TOMOHON TIMUR, KOTA TOMOHON
}

\author{
Riane W. Senewe \\ Agnes E. Loho \\ Mex L. Sondakh
}

\begin{abstract}
This study aims to identify the supporting and obstacle factors of strawberry farming in the Rurukan and Rurukan Satu Villages. The study was carried out in three months, July to September 2016. The data used in this study were primary and secondary data. The total respondents were seven farmers consisted of 5 farmers who were still farming strawberry and two farmers who previously cultivated strawberry. The analysis used in this study was a descriptive analysis of the characteristics of the farmers and to identify the factors supporting and obstacle factors in strawberry farm. The results showed that the factors supporting the farming of strawberries were the availability strawberry seeds, the availability of organic fertilizers, natural conditions and selling prices as well as market share. While the obstacle factors in the farming of strawberries were extreme weather, land, capital, the price of fertilizer. *ael*.
\end{abstract}

Keywords: Strawberries, supporting factors, obstacle factors, urban villages of Rurukan and Rurukan Satu, Tomohon City

\begin{abstract}
ABSTRAK
Penelitian ini bertujuan untuk mengidentifikasikan faktor penunjang dan penghambat usahatani stroberi di Kelurahan Rurukan dan Rurukan Satu. Lamanya penelitian dilakukan selama tiga bulan dari bulan Juli hingga bulan Oktober tahun 2016. Data yang digunakan dalam penelitian ini adalah data primer dan data sekunder. Total petani yang dijadikan responden adalah 7 orang yang terdiri dari 5 petani yang masih berusahatani stroberi dan 2 petani yang sudah tidak mengusahakan stroberi. Analisis yang digunakan dalam penelitian ini adalah analisis deskriptif menyangkut karakteristik petani dan mengidentifikasi faktor penunjang dan penghambat usahatani stroberi. Hasil penelitian menunjukkan bahwa faktor penunjang dalam usahatani stroberi adalah ketersediaan bibit stroberi, ketersediaan pupuk organik, kondisi alam dan harga jual serta pangsa pasar. Sedangkan faktor penghambat dalam usahatani stroberi adalah cuaca yang ekstrim, lahan, modal, harga pupuk.
\end{abstract}

Kata kunci: Stroberi, faktor penunjang, faktor penghambat, Kelurahan Rurukan dan Rurukan Satu, Kota Tomohon 


\section{PENDAHULUAN}

\section{Latar Belakang}

Stroberi atau strawberry dalam bahasa Inggris, merupakan salah satu komoditi buahbuahan yang penting di dunia, terutama untuk negara-negara beriklim subtropis. Permintaan konsumen terhadap buah stroberi cenderung meningkat dari tahun ke tahun. Daya serap pasar yang semakin tinggi mencerminkan bahwa usahatani stroberi mempunyai prospek cerah. Di negara-negara yang beriklim subtropis pengembangan usahatani stoberi dijadikan sebagai salah satu sumber pendapatan utama petani. Pola dan sistem pengembangan budidaya stroberi telah dipadukan dengan sektor pariwisata, yaitu menciptakan kebun agrowisata (Rukmana, 2008).

Stroberi merupakan salah satu jenis buahbuahan yang memiliki nilai ekonomis yang tinggi. Beberapa petani, khususnya di daerah dataran tinggi telah melakukan budidaya stroberi secara komersial. prospek usaha stroberi sangat menjanjikan. Stroberi sering ditemukan di pasar swalayan serta supermarket-supermarket ialah stroberi jenis Hibrida yang dihasilkan dari persilangan Fragaria virgiana $L$ var Duchesne asal Amerika dengan Fragali choiloensi $L$ asal Chili (Darwis, 2007).

Menurut Gunawan (2006) Permintaan stroberi di Indonesia bisa dikatakan cukup tinggi karena buah stroberi mempunyai peluang pasar yang semakin luas, karena buah stroberi ini tidak hanya dapat dikonsumsi langsung tetapi stroberi juga dapat diolah menjadi sirup, selai, dodol, manisan, jus, dan bahan baku pembantu pembuat es krim dan kue, serta berguna bagi kesehatan.

Salah satu daerah yang telah mengembangkan usahatani stroberi di Sulawesi Utara adalah kelurahan Rurukan dan Rurukan satu, daerah ini memiliki dataran tinggi yang merupakan daerah yang cocok untuk tanaman stroberi dan berpotensial untuk mengembangkan tanaman stroberi, karena stroberi dapat tumbuh dengan baik di daerah ini. Usahatani stroberi berpotensi untuk dikembangkan di kelurahan Rurukan dan Rurukan satu karena adanya kesesuaian agroklimatnya untuk pertumbuhan tanaman stroberi dan peluang pasar yang masih terbuka.

Usahatani stroberi mulai diperkenalkan pada tahun 2006 dan telah dibudidayakan petani di Rurukan pada tahun 2009. Pada tahun 2016, ketersediaan buah stroberi di supermarket berkurang sehingga buah stroberi harus di ambil dari ciwidey Bandung dan di import dari jepang.

Hal ini menyebabkan kualitas dari stroberi berkurang karena proses pengiriman yang memakan waktu. Oleh karena itu peneliti ingin mengetahui faktor penyebab kelangkaan buah stroberi yang ada di kelurahan Rurukan dan Rurukan satu untuk itu perlu diketahui faktor penunjang dan penghambat usahatani stroberi dikelurahan Rurukan dan Rurukan satu di kecamatan Tomohon timur, kota Tomohon.

\section{Rumusan Masalah}

Berdasarkan latar belakang yang telah diuraikan diatas, maka yang menjadi perumusan masalah dalam penelitian ini adalah faktor apa saja yang menjadi penunjang dan penghambat usahatani stroberi di kelurahan Rurukan Dan Rurukan satu di Kecamatan Tomohon Timur Kota Tomohon?

\section{Tujuan Penelitian}

Penelitian ini dilakukan dengan tujuan untuk mengidentifikasi faktor penunjang dan penghambat usahatani stroberi dikelurahan Rurukan Dan Rurukan Satu.

\section{Manfaat Penelitian}

1. Bagi petani, mampu memberikan informasi bagi petani stroberi dalam rangka meningkatkan produktifitas dan memudahkan kegiatan pengembangan usahatani stroberi. 
2. Bagi peneliti, penelitian ini dapat menambah pengetahuan dan sebagai salah satu syarat kelulusan untuk memperoleh gelar sarjana di Fakultas Pertanian Universitas Sam Ratulangi Manado.

3. Bagi pihak lain, penelitian ini dapat menjadi bahan pertimbangan dalam melakukan penelitian sejenis.

\section{METODOLOGI PENELITIAN}

\section{Waktu dan Tempat Penelitian}

Penelitian ini dilaksanakan dikelurahan Rurukan dan Rurukan satu kecamatan Tomohon Timur, Kota Tomohon. Pemilihan Lokasi penelitian berdasarkan kriteria bahwa dikelurahan Rurukan dan Rurukan satu yang mengembangkan usahatani stroberi. Penelitian berlangsung selama 3 (tiga) bulan yakni mulai bulan Juli sampai bulan September tahun 2016 yang dimulai dari persiapan sampai laporan hasil penelitian.

\section{Metode Pengumpulan Data}

Penelitian ini menggunakan data primer dan data sekunder. Data primer diperoleh dari hasil Wawancara langsung dengan petani stroberi sebagai responden berdasarkan daftar pertanyaan (quesioner) yang telah disiapkan. Sedangkan, Data sekunder diperoleh dari instansi yang terkait langsung dengan penelitian dalam hal ini kantor Kelurahan Rurukan dan Kelurahan Rurukan satu.

\section{Metode Pengambilan Sampel}

Pengambilan sampel dalam penelitian ini adalah petani stroberi yang ada di kelurahan Rurukan dan Rurukan satu dan populasi 30 petani stroberi, lembaga dan perangkat desa. Dari 30 petani berdasarkan sensus diambil 7 petani yang mempunyai lahan sendiri dalam usahatani stroberi, dan diambil 5 petani stroberi yang masih aktif dan 2 petani stroberi yang sudah tidak lagi menanam stroberi sebagai sample yang ada relevansinya dengan tujuan penelitian.

\section{Deskripsi variabel penelitian}

1. Karakteristik petani responden Umur: usia responden (tahun), Tingkat pendidikan: tingkat pendidikan formal, Jumlah tanggungan keluarga: Jumlah yang menjadi tanggungan kepala keluarga.

2. Luas lahan yang dikelola petani dalam usahatani stroberi (Ha).

3. Faktor Penunjang dan penghambat usahatani stroberi di identifikasikan menurut sapta usahatani yang meliputi ketersediaan benih, pupuk, tenaga kerja, lahan, modal dan alat mesin pertanian, panen dan pasca panen sampai pemasaran hasil pertanian.

\section{Metode Analisis Data}

Hasil penelitian dianalisis secara deskriptif berupa identifikasi karakteristik petani stroberi dan faktor penunjang dan penghambat usahatani stroberi.

\section{HASIL DAN PEMBAHASAN}

\section{Deskripsi Wilayah Penelitian}

Kelurahan Rurukan terletak di Kecamatan Tomohon Timur Kota Tomohon Provinsi Sulawesi Utara dan berada pada ketinggian 1100-1300 dpl dengan luas wilayah \pm 350 Ha. Sedangkan Kelurahan Rurukan Satu terletak di Kecamatan Tomohon Timur Kota Tomohon Provinsi Sulawesi Utara dan berada pada ketinggian 1080 dpl dengan luas 155,8 Ha. Daerah Rurukan dan Rurukan satu menjadi tempat yang cocok untuk budidaya tanaman stroberi karena daerahnya yang agroklimat.

\section{Keadaan Penduduk (Demografi)}

Data demografis Kelurahan Rurukan pada tahun 2015 memiliki jumlah penduduk sebanyak 1285 jiwa yang terdiri dari laki-laki 648 jiwa sedangkan perempuan terdiri dari 
637 jiwa. Penduduk di kelurahan Rurukan Satu berjumlah 1256 jiwa, dengan perincian laki-laki 635 jiwa dan perempuan 621 jiwa.

Adapun mata pencaharian penduduk Kelurahan Rurukan dan Rurukan satu cukup beragam, yaitu sebagai petani, buruh tani, PNS/Guru, Wirausaha, Karyawan Swasta, POLRI, Pengusaha, dan Pensiunan. Sebagian besar Penduduk dikelurahan Rurukan bekerja disektor pertanian, yaitu sebesar 112 jiwa atau $48,9 \%$, dan penduduk yang berprofesi sebagai buruh tani sebanyak 32 jiwa atau 13,9\%, sedangkan dikelurahan Rurukan satu penduduk yang bekerja disektor pertanian yaitu sebanyak 109 jiwa atau 47,1\% dan penduduk yang berprofesi sebagai buruh tani sebanyak 35 jiwa atau $15,1 \%$.

\section{Karakteristik Responden}

Karakteristik responden yang menjadi narasumber dalam penelitian ini yang memiliki lahan stroberi yaitu sebanyak 7 petani, 5 petani yang masih aktif menanam stroberi dan 2 petani yang sudah tidak menanam stroberi. Identitas responden meliputi umur, tingkat pendidikan, jumlah tanggungan keluarga dan luas lahan.

\section{Umur Responden}

Umur Responden Kelurahan Rurukan dan Rurukan satu dengan usia rata-rata 44 tahun. Usia 30-45tahun terdapat 1 Responden sedangkan yang berumur 46-55tahun 3 responden. Sedangkan umur dari petani kelurahan Rurukan satu berkisar 30-45 tahun terdapat 3 responden. Usia produktif dengan kemampuan petani dalam bekerja.

\section{Pendidikan Responden}

Pendidikan merupakan salah satu faktor yang menentukan produktifitas kerja, sikap serta kemampuan seseorang dalam berfikir dan bertindak. Berdasarkan hasil penelitian, tingkat pendidikan responden mulai dari Sekolah Menengah Keatas (SMA).Dan Perguruan Tinggi (S1). Petani dengan tingkat pendidikan SMA sebanyak 5 orang atau presentase $71,4 \%$. Sedangkan untuk responden petani yang berpendidikan $\mathrm{S} 1$ berjumlah 2 orang atau $28,5 \%$.

\section{Tanggungan Keluarga}

Jumlah anggota keluarga petani kelurahan Rurukan dan Rurukan Satu memiliki tanggungan keluarga $\leq 3$ orang petani sebanyak 3 orang, tanggungan 4-6 orang petani sebanyak 4 orang.

\section{Mata Pencaharian}

Mata pencaharian sebagai petani sebanyak 4 orang responden atau 57,2\% dan 3 Orang atau $42,8 \%$ memiliki pekerjaan selain bertani yakni sebagai karyawan dan wirausaha.

\section{Luas Lahan}

Luas lahan yang ditanami stroberi di kelurahan rurukan berkisar antara 0,01-0,16 Ha dengan rata-rata kepemilikkan seluas 0,08 Ha.

\section{Usahatani stroberi dikelurahan Rurukan dan Rurukan Satu}

Usahatani stroberi di kelurahan Rurukan dan Rurukan satu sudah dikenal sejak tahun 2006 oleh petani streoberi dan dikembangkan. Sistem pengelolaan usahatani stroberi di kelurahan Rurukan dan Rurukan satu meliputi Pembibitan, pengelolaan media tanam, penanaman, pemangkasan, pemupukan, pengendalian hama dan penyakit, panen dan pasca panen, dan pemasaran.

\section{1) Pembibitan}

Pada umumnya jenis bibit stroberi yang digunakan untuk stroberi di Rurukan dan Rurukan satu adalah varietas California, dan varietas festival. Terdapat perbedaan diantara kedua varietas ini yaitu varietas Festival lebih unggul dibandingkan varietas California. Keunggulannya adalah varietas Festival menghasilkan buah yang berukuran sedang, berwarna merah dan memiliki rasa yang lebih manis sedangkan varietas California menghasilkan buah yang berwarna kemerahan, ukurannya lebih kecil dengan rasa yang asam. 
Bibit yang di tanam di Kelurahan Rurukan dan Rurukan satu diperoleh dari tanaman induk yang berumur 1-2 tahun yang sehat dan produktif selanjutnya rumpun yang telah dipilih telah memiliki akar sulur pertama dan kedua kemudian kedua akar sulur ini dipotong lalu bibit di tanam didalam polibag 18 x $15 \mathrm{~cm}$ yang berisi campuran tanah dan pupuk kandang. Setelah tingginya $10 \mathrm{~cm}$ dan berdaun rimbun, bibit siap untuk dipindahkan ke bedengan dikebun.

\section{2) Pengolahan media tanam}

Pengolahan media tanam di kelurahan Rurukan dan Rurukan satu menggunakan media tanam polybag lalu dipindahkan ke kebun, namun prosesnya harus diolah dengan baik kemudian keringanginkan 15-30 hari selanjutnya membuat bedengan dengan lebar 80 x $120 \mathrm{~cm}$, tinggi 30-40 cm, panjang disesuaikan dengan lahan, jarak antar bedengan $60 \mathrm{~cm}$ lebar bawah $60 \mathrm{~cm}$, lebar atas $40 \mathrm{~cm}$, tinggi $30-40 \mathrm{~cm}$, panjang disesuaikan dengan lahan, jarak antar bedengan $60 \quad \mathrm{~cm}$. Selanjutnya dikeringanginkan lagi selama 15 hari kemudian petani menyirami lahan bedengan hingga lembab selanjutnya dipasangkan mulsa plastik perak untuk menutupi bedengan kemudian ujung mulsa tersebut dikuatkan dengan bantuan bambu berbentuk $U$, selanjutnya membuat lubang diatas plastik dengan menggunakan kaleng bekas susu kental manis yang diisi dengan bara api dengan tujuan agar kaleng menjadi panas dan lebih mudah membuat lubang. Jarak antar lubang dalam barisan $30 \mathrm{~cm}$, sehingga jarak tanam menjadi $20 \mathrm{~cm}$ x $30 \mathrm{~cm}$.

\section{3) Penanaman}

Petani stroberi di kelurahan Rurukan dan Rurukan satu biasanya melakukan penanaman stroberi di lahan tanah secara langsung dengan menggunakan metode seperti bedengan. Petani stroberi dikelurahan rurukan dan rurukan satu biasanya menggunakan satu orang tenaga kerja laki- laki dengan upah Rp.100.000/hari dalam proses penanaman.

Untuk proses penanaman hal pertama yang dilakukan petani adalah dengan menyiram polybag berisi bibit kemudian bibit di keluarkan bersama media tanamnya dengan hati hati lalu tanam satu bibit di lubang tanam dan padatkan tanah di sekitar pangkal batang kemudian sirami tanah disekitar pangkal batang sampai lembab, selanjutnya tanaman stroberi siap di pindahkan di kebun untuk ditanam.

\section{4) Penyiangan}

Proses penyiangan yaitu pemberantasan gulma atau tanaman liar. Gulma atau tanaman liar bisa mengganggu pertumbuhan dan kesehatan tanaman. Gulma atau tanaman liar harus perlu disiangi pada umumnya petani di kelurahan Rurukan dan rurukan satu melakukan pemberantasan gulma secara mekanis yaitu dilakukan dengan menggunakan alat yaitu parang dan cangkul serta tenaga secara langsung dengan mencabut rumput atau tanaman liar tersebut. Kegiatan ini harus dilakukan sesering mungkin agar tanaman dapat terhindar dari tanaman pengganggu dan petani sudah cukup baik karena sudah semua petani stroberi di daerah penelitian melakukan penyiangan secara teratur.

\section{5) Pemangkasan}

Tanaman yang terlalu rimbun atau terlalu banyak daun harus dipangkas. Pemangkasan dilakukan secara teratur terutama membuang daun-daun tua atau rusak dan terkena hama, daun tersebut apabila tidak dibuang akan memenuhi bedengan. Sedangkan daun yang terkena hama bila tidak dibuang akan menjadi sumber infeksi ke daun yang lain, pemangkasan ini dilakukan secara rutin. Hasilnya dengan melakukan pemangkasan ini dapat meningkatkan produktivitas tanaman sehingga menghasilkan buah yang maksimal. 
6) Pemupukan

Proses pemupukan bertujuan memberikan nutrisi pada tanaman. Jenis pupuk yang digunakan petani stroberi di kelurahan Rurukan dan rurukan satu yaitu pupuk organik (pupuk kandang dan biotech) untuk pemberian nutrisi pada tanaman. pupuk kandang berasal dari kotoran hewan ternak yaitu hewan ternak sapi dan kuda. Pupuk kandang diperoleh dari ternak sendiri ada juga yang dibeli seharga Rp.15.000/ karung.

Penggunaan pupuk kandang hanya dilakukan satu kali yaitu pada persiapan lahan atau hanya dilakukan pada panen I dimana pupuk hanya digunakan untuk menyuburkan tanah agar kondisi tanah menjadi lebih produktif dan menghasilkan produksi stroberi yang maksimal. Sedangkan untuk penggunaan pupuk organik biotech dilakukan pada panen II sampai dengan panen VIII dengan tujuan memberikan nutrisi pada batang dan akar agar supaya tetap subur dan memperoleh produksi buah yang maksimal. Pupuk Biotech diperoleh dari toko pertanian.

\section{7) Hama dan penyakit}

Masalah hama dan penyakit yang sering mengganggu petani stroberi di Kelurahan Rurukan dan Rurukan Satu yang banyak menimbulkan kerugian bahkan sampai mengakibatkan gagal panen. Jenis hama dan penyakit yang mengganggu usahatani stroberi yang ada di Rurukan dan rurukan adalah kutu daun yaitu kutu berwarna kuning kemerahan yang berukuran kecil 1-2 mm, hidup bergerombol dipermukaan bawah daun bagian yang diserang adalah permukaan daun bagian bawah, kuncup bunga, pucuk atau batang bunga.

Petani di kelurahan rurukan dan rurukan satu melakukan pencegahan dengan menggunakan pestisida Biotop. Kemudian adapun penyakit yang mengganggu tanaman stroberi di kelurahan rurukan seperti busuk buah matang yaitu bagian yang diserang adalah buah yang menjadi busuk lunak, berair, bila di tekan keluar cairan keruh dan juga jamur. Petani melakukan pencegahan dengan menggunakan fungisida.

8) Panen dan pasca panen

Tanaman stroberi mulai berbunga pada umur 2 bulan setelah tanam. Setelah tanaman berumur 4 bulan mulai diarahkan untuk lebih produktif. Panen dilakukan dengan dipetik atau digunting bagian tangkai buah beserta kelopaknya, yang dilakukan empat kali dalam jangka waktu panen selama dua minggu. Stroberi dapat dipanen ketika buah sudah agak kenyal dan agak empuk, kulit buah didominasi warna merah atau hijau kemerahan hingga kuning kemerahan, buah stroberi hasil panen kemudian disimpan dalam suatu wadah dengan hati-hati agar tidak memar. Petani kemudian melakukan pengemasan stroberi yang biasa dikemas dalam wadah plastik transparan atau putih dan siap untuk di jual dan di pasarkan.

\section{9) Pemasaran}

Pemasaran buah stroberi di kelurahan Rurukan dan Rurukan Satu ini didukung dengan kondisi agrowisata yang menjadi daya tarik kawasan wisata Rurukan ini dengan memanfaatkan hal tersebut petani membuka tempat penjualan buah stroberi didekat lokasi penanaman stroberi atau dibukit temboan.

Hal ini banyak menarik konsumen yang datang membeli produk stroberi karena bisa membeli produk stroberi dengan cara memetik sendiri untuk anak sekolah yang melakukan study tour dan wisatawan luar yang berkunjung ke perkebunan stroberi. Konsumen yang memetik langsung di kebun petani kemudian di timbang beratnya dan biasanya petani menjual produk stroberi ini dengan harga Rp.12.000/gram atau 1 packing stroberi, ada juga yang didistribusikan ke supermarket yang ada di tomohon yaitu cool dan juga ada yang didistribusikan di supermarket manado seperti freshmart dengan harga Rp.120.000- 
$150.000 / \mathrm{kg}$ atau sekitar 5 kemasan buah stroberi.

Faktor Penunjang dan Penghambat Usahatani Stroberi

\begin{tabular}{|c|c|c|}
\hline Keterangan & Penunjang & Penghambat \\
\hline Sarana & Bibit stroberi & Lahan \\
\hline Produksi & $\begin{array}{c}\text { Pupuk Organik } \\
\text { Tenaga kerja }\end{array}$ & $\begin{array}{l}\text { Modal } \\
\text { Alat mesin } \\
\text { pertanian }\end{array}$ \\
\hline Budidaya & $\begin{array}{c}\text { Iklim } \\
\text { Pengetahuan } \\
\text { petani } \\
\text { Informasi }\end{array}$ & $\begin{array}{c}\text { Cuaca } \\
\text { ekstrim } \\
\text { Harga pupuk }\end{array}$ \\
\hline $\begin{array}{l}\text { Panen dan } \\
\text { pasca panen }\end{array}$ & $\begin{array}{l}\text { Pengetahuan } \\
\text { pengolahan } \\
\text { buah stroberi }\end{array}$ & Modal \\
\hline Pemasaran & $\begin{array}{c}\text { Harga jual } \\
\text { Pangsa pasar } \\
\text { Manfaat } \\
\text { stroberi }\end{array}$ & Harga beli \\
\hline
\end{tabular}

1. Faktor penunjang

a. Sarana produksi

1) Bibit stroberi merupakan penunjang paling pokok untuk petani stroberi, bibit yang dimiliki adalah varietas yang berasal dari California dan dari jepang, dalam sarana produksi karena petani sudah dapat menyediakan bibit sendiri yang diperoleh dari sulur yang dirundukkan ke dalam wadah gelas aqua atau polybag yang sudah di isi tanah.

2) Pupuk organik berupa pupuk kandang yang dapat dibuat sendiri oleh petani yang merupakan fermentasi dari pupuk kandang yang dibeli dari Tomohon. Pupuk kandang atau kompos dibuat dari kotoran ternak babi, kambing, kelinci, kerbau, kuda, sapi, dan ungags
3) Tenaga kerja yang berada di kelurahan rurukan dan rurukan satu cukup tersedia karena mayoritas warga kelurahan rurukan adalah petani.

b. Budidaya

1) Iklim atau kondisi alam yang sangat mendukung dalam pengembangan usahatani stroberi daerah Rurukan dan Rurukan satu menjadi tempat yang cocok untuk budidaya tanaman stroberi.

2) Pengetahuan petani yang sudah mengetahui cara membudidayakan stroberi dengan mengikuti pelatihan, penyuluhan dan belajar sendiri dalam pengembangan usahatani stroberi.

3) Informasi juga menjadi penunjang bagi ushatani stroberi karena petani yang berada di kelurahan rurukan selalu mendapatkan informasi mengenai budidaya stroberi yang baik.

c. Panen dan pasca panen

Stroberi dipanen ketika buah sudah agak kenyal dan agak empuk, Pengetahuan pengolahan buah stroberi yang sudah diketahui oleh petani namun belum bisa untuk dikembangkan secara lanjut.

d. Pemasaran

Buah stroberi sangat diminati konsumen dengan rasanya yang manis dan asam serta manfaat yang terkandung dalam buah stroberi membuat konsumen ingin mengkonsumsinya oleh karena itu permintaan pasar untuk buah stroberi cukup tersedia atau kontinu. Sehingga harga jual stroberi di tingkat petani Rp. 12.000 - Rp. 15.000 tiap kemasan, sedangkan di supermarket dengan harga Rp. 15.500 - 36.800 per kemasan. Tiap kemasan diisi 100-120gram, harga ini menunjukan bahwa harga stroberi akan memberikan pendapatan yang tinggi yaitu Rp 120.000-150.000 tiap kilogram. 


\section{Faktor Penghambat}

a. Sarana produksi

1) Keterbatasan lahan dikarenakan banyaknya petani yang masih menggunakan agrokimia sehingga petani yang sudah mulai menerapkan pertanian organik menjadi kesulitan mencari lahan yang bebas agrokimia dan sebagian petani belum mempunyai lahan lain yang bisa ditanami stroberi.

2) Petani stroberi dikelurahan Rurukan dan Rurukan satu sering mengalami kesulitan dalam hal permodalan. Modal menjadi penghambat dalam usahatani stroberi karena untuk membeli saranasarana produksi dan pembiayaan tenaga kerja memerlukan modal yang banyak, kurangnya modal menjadi penghambat untuk pengembangan usahatani stroberi.

3) Alat dan mesin pertanian menjadi penghambat dikarenakan tidak ada ketersediaan alat pertanian untuk pembuatan pupuk oleh petani karena kurangnya modal sehingga petani tidak dapat membeli alat mesin pertanian

b. Budidaya

1) Cuaca ekstrim merupakan faktor penghambat yang paling menentukan keberhasilan usahatani stroberi organik. Apabila curah hujan terlalu tinggi maka tanaman yang hanya ditanam pada area terbuka akan cepat membusuk, sebaliknya musim kemarau yang berkepanjangan membuat banyak tanaman mati. Panjangnya musim kemarau pada tahun 2015 menyebabkan produksi stroberi turun $80 \%$ sehingga menyebabkan kelangkaan stroberi di pasaran.
2) Harga pupuk yang mahal menjadi penghambat petani karena sebagian petani yang menggunakkan pupuk organik dengan pengolahan sendiri harus membeli kotoran kandang ke petani yang memiliki kotoran kandang.

c. Panen dan pasca panen

Modal menjadi penghambat dalam petani karena ketersediaan modal petani belum bisa mendanai pengembangan dan pengolahan buah stroberi sehingga menjadi suatu produk olahan yang dapat di jual.

d. Pemasaran

Meskipun permintaan buah stroberi kontinu namun petani stroberi belum bisa mensuplay buah stroberi terus menerus. Harga stroberi yang tergolong tinggi bagi responden yang berpendapatan rendah dengan harga stroberi yaitu Rp. 12.000 Rp. 15.000 per 100-120gram harga tersebut jika dibeli langsung ke petani stroberi, sedangkan harga di supermarket yaitu Rp. 15.500 per 100-120gram, namun sebagian petani tidak menjual ke supermarket karena sistem pembayaran dari supermarket yang biasanya habis terjual baru di bayar. Juga jika terdapat buah yang busuk tidak akan dihitung dalam pembayaran sehingga hal ini menyebabkan petani stroberi lebih memilih menjual sendiri atau langsung dibandingkan harus dijual ke supermarket.

\section{KESIMPULAN DAN SARAN}

\section{Kesimpulan}

Faktor penunjang dan penghambat utama usahatani stroberi di kelurahan Rurukan dan Rurukan satu adalah:

1. Faktor penunjang usahatani stroberi ialah Bibit stroberi, pupuk organik, syarat tumbuh yang sesuai kondisi alam dan harga jual serta pangsa pasar. 
2. Faktor penghambat untuk petani stroberi dalam pengembangan usahataninya yakni seperti cuaca yang ekstrim, lahan, modal, harga pupuk.

\section{Saran \\ Kepada petani \\ 1. Agar petani lebih focus dalam mengembangkan usahatani stroberi.}

2. Agar lebih kreatif dalam mempersiapkan tindakan pencegahan menghadapi cuaca ekstrim.

\section{Kepada pemerintah}

Agar pemerintah dapat membantu usahatani stroberi dirurukan dan rurukan satu dengan memberikan bantuan atau pinjaman modal kepada petani stroberi

\section{DAFTAR PUSTAKA}

Aswita, A. P. 2007. Analisis Usahatani Strawberry (Studi kasus : Desa Tongkoh Kecamatan Tiga Panah dan Desa Korpri Kecamatan Brastagi Kabupaten Karo). Skripsi. Medan : Universitas Sumatera Utara

Assary. 2001. Analisis Pendapatan

Usahatani dan Pemasaran Komoditi Jahe (Kasus Desa Kalapanunggal, Kecamatan Kalapanunggal, Kabupaten Sukabumi, Propinsi Jawa Barat). Skripsi. Bogor : Institut Pertanian

Bogor.

Agus Kurnia. 2005. Petunjuk Praktis Budi Daya Stroberi. Agro Medika

Pustaka. Jakarta

Arifin, Bustanul. 2004. Analisis Ekonomi Pertanian Indonesia. Kompas Media Nusantara. Jakarta.
Adi, R.K. 2006., Strategi Pemasaran Strawberry di Kecamatan Tawangmangu Kabupaten Karanganyar. Jurnal Sosial Ekonomi Pertanian dan Agribisnis. Fakultas Pertanian. Universitas SebelasMaret

Anonimous. 2001. Pembangunan Sistem Agribisnis Sebagai Penggerak Ekonomi Nasional. Departemen Pertanian, Jakarta. Edisi Pertama.

Atmoko W \& Kurniawati I. 2009.. Sebuah Respon Realistik Perilaku Konsumen Di Masa Krisis Swamedikasi Bisnis dan Kewirausahaan.

Budiman S \& Saraswati D 2006., Berkebun Stroberi Secara Komersial, Penebar Swadaya, Jakarta

Daniel, M. 2004. Pengantar Ekonomi Pertanian. Bumi Aksara : Jakarta.

Febriano, S.N.Purnomo 2008., Strategi Pengembangan Agribisnis Stroberi Di Kabupaten Purbalingga. Skripsi Universitas Sebelas Maret Surakarta.

Firdaus, M, 2008., Manajemen Agribisnis, PT Bumi Aksara : Jakarta.

Furqon, C. (2014)., Analisis Manajemen Dan Kinerja Rantai Pasokan Agribisnis Buah Stroberi Di Kabupaten Bandung. Image. Bandung

Gunawan, 2006., Usahatani Stroberi Lokal. Penerbit Armico. Bandung

Hernanto, F. 1993. Ilmu Usahatani. Swadaya. Jakarta.

Kurnia, A. 2005. Petunjuk Praktis Budidaya Stroberi. PT. AgroMedia Pustaka. Jakarta 
Notohadinegoro, T., Johara. 2005. Faktor Tanah dalam Pengembangan Hortikultura. UGM press, Yogyakarta.

Octavianthy, H. 2006., Analisis Pengembangan Agribisnis Komoditi Stroberi diKecamatan Tawangmangu Kabupaten Karanganyar. Skripsi. Fakultas Pertanian Universitas Sebelas Maret, Surakarta.

Rahardi F, Indriyani Y.V dan Haryono 2003., Agribisnis Tanaman Buah Penebar Swadaya, Jakarta.

Rahim, abd., Hastuti, R, D, Diah. 2007. Ekonometrika Pertanian. Penebar Swadaya: Jakarta

Rukmana, R., 1998, Stroberi; Budidaya dan Pascapanen, Kanisius, Yogyakarta.

Rukmana, R., 2008. Mari Bertanam Stroberi. PT Gramedia Utama. Jakarta

Rumengan, M. 2015. Kajian Kinerja Agribisnis Starwberry Organik Study Kasus Kelompok Tani Kina Kelurahan Rurukan Dan Kelompok Tani Agape Kelurahan Rurukan Satu. Skripsi Fakultas Pertanian Universitas Sam Ratulangi, Manado.
Saragih, B., 2010., Agribisnis Paradigma Baru Pembangunan Ekonomi Berbasis Pertanian. Pustaka Wirausaha Muda. Bogor.

Soekartawi, 2002., Analisis Usaha Tani, UI - Press, Jakarta.

Soekartawi. 2003., Agribisnis; Teori dan Aplikasinya. Grafindo Persada. Jakarta

Soekartawi, Soeharjo A, Dillon JL, dan Hardaker JB. 2011., Ilmu Usahatani dan Penelitian untuk Pengembangan Petani Kecil. Jakarta : UI Press

Tandisau, P dan Herniwati. 2009. Prospek Pengembangan Pertanian Organik di Sulawesi Selatan. Makalah disajikan pada Prosiding Seminar Nasional Serealia 2009. Balai Pengkajian Teknologi Pertanian Sulawesi Selatan. Makasar.

Tambunan, Tulus.T.H. 2003. Perkembangan Sektor Pertanian di Indonesia: Beberapa Isu Penting. Jakarta. Ghalia, Indonesia.

Winata G.L 2003. Stroberi, Penebar Swadaya. Jakarta 